\section{Fallacy of perfection harms peer review}

Voltaire wrote in 1772, "the best is the enemy of the good", warning against the fallacy that something is worthless if it is not perfect - a sentiment that seems common in scientific peer review today.

The history of science has taught us that most progress has come from exploring flawed hypotheses and imperfect models. We must always strive for the better study, the better model, the better analysis. As experienced reviewers, however, we contend that seeking ultimate perfection is not the same as accepting nothing less here and now. Scientific progress depends on such compromise - provided that potential caveats are recognized.

If a model is the most technically and ethically feasible approach available, and is better than random guessing, then it has some merit in advancing knowledge. Useful developments in biology, for example, have come from in vitro systems that do not reflect in vivo conditions, and from animal models that do not necessarily predict human disorders.

The aim should be to utilize models, despite their imperfections, while continuing to improve them. It is unrealistic to hold progress in science to standards of perfection and certainty: progress is usually incremental and iterative. James C. Zimring BloodworksNW; and University of Washington, Seattle, USA. Steven L. Spitalnik Columbia University, New York, USA. jzimring@bloodworksnw.org

\section{Hallmark labs with a replicability record}

I am concerned that the tension between good research practice and scientific success is rising, despite recent efforts to shore up replicability (see Nature http://doi.org/bpmf; 2016).

As others have noted, high-quality research should start in the lab, by validating cell lines and reagents, for example, and end with serious, meticulous review. That rarely happens because it is time-consuming, and time is every scientist's worst enemy - particularly for young researchers who face stiff competition in the scientific job market.

To resolve this conflict, we need to work out how to change the incentive system so that it fosters a culture of good, responsible research. Reproducibility could be underpinned by a strict set of rules — including, say, systematic use of power analysis and samplesize estimation. To promote compliance and to counter any negative effect on productivity, and hence on competition for funding, labs with a record of high-quality research could be accredited with an international certificate of approval. An independent, not-for-profit organization might be responsible for awarding such certificates. Mattia Andreoletti European Institute of Oncology, Milan, Italy. mattia.andreoletti@ieo.eu

\section{Stuck between a rock and a hard place}

We question the basis of July's ruling by an international tribunal that the disputed Spratly Islands (Nan-sha Islands) in the South China Sea are merely rocks (see Nature 535, 334-335; 2016).

According to the United Nations Convention on the Law of the Sea, which is signed by 178 countries, an island is defined by three elements: it is a natural formation; it lies in the same territory and economic zone as the surrounding sea; and it can sustain human habitation or have an economic life of its own (see go.nature.com/2bj4sit).

One of the disputed islands, Taiping Island, fulfils all three criteria, having its own freshwater resources (see go.nature. com/2biujnv; in Chinese). There is also human habitation and economic activity on several of the other islands.

In our view, the international court seems to have interpreted an island's third defining element as requiring no external resources to sustain human settlement. If that were the case, the Maldives, Singapore and Hong Kong should probably be considered as rocks - they bring in gas and must obtain much of their fresh water by import and desalinization or from rain water.

Yingchao $\mathrm{Hu}$, Liangjun $\mathrm{Hu}$

Northeast Normal University, Changchun, China.

hulj068@nenu.edu.cn

\section{Rate oceans' capital to help achieve SDGs}

Goal 14 of the United Nations'

Sustainable Development

Goals (SDGs) is dedicated

to conserving and using the oceans and their resources for sustainable development. We suggest that a 'gross marine product' (GMP) index - a measure of the oceans' natural capital - would be invaluable for achieving this goal.

The seas provide us with food, materials, livelihoods and recreation. Managing these ecosystem services effectively can help us to eradicate poverty, develop sustainable economies and adapt to global environmental changes. Yet international-resource experts and national strategies still focus largely on goods and services delivered by terrestrial ecosystems (see go.nature. com/2bcqjr0).

A GMP index would provide a measure of marine ecosystem goods and services on a national or global scale, derived from estimates for individual oceans. More international research will be necessary to underpin these estimates. The results would inform decision-makers, the private sector and the public on how they could help to achieve goal 14, as well as the 60 targets across most of the 17 SDGs that are relevant to the sustainable development of coastal zones. An integrated programme that measures, monitors and assesses the health of human-ocean systems should oversee their sustainability.

Yonglong Lu ${ }^{\star}$ Research Center for Eco-Environmental Sciences, Chinese Academy of Sciences, Beijing, China.

yllu@rcees.ac.cn

${ }^{\star}$ On behalf of 5 correspondents (see go.nature.com/2biddczfor full list).

\section{Could Pokémon Go boost birding?}

In a week when the game Pokémon Go topped 15 million downloads, I had a salutary reminder that urban humans risk losing touch with nature - with possible negative implications for the future of fieldwork in conservation and ecology (see also Nature 535, 323-324; 2016).

As I set out to go birdwatching in Queensland's rainforest, my 14-year-old daughter grabbed her smartphone to search for rare Pokémon in every nearby park, beach and town. The Pokémon are an extremely speciose group that undergo continuous evolution and have particular ecological needs. Embedded in nature by an augmented reality, they hold the same naturalistic delight for my daughter as a cassowary (Casuarius casuarius) does for me.

At the end of my day, I had counted three 'lifers' (my first sightings of Platalea regia, Entomyzon cyanotis and Nectarinia jugularis) and my daughter had spotted 30 Pokémon. I was delighted when she asked me about a bird that appeared beside a Pidgey on her screen. It was a real laughing kookaburra (Dacelo novaeguineae).

Fabio de Oliveira Roque Federal University of Mato Grosso do Sul, Brazil.

roque.eco@gmail.com 